\title{
O método biográfico interpretativo na compreensão de experiências e expressões de gestantes usuárias de um serviço de saúde*
}

\author{
THE INTERPRETATIVE AND BIOGRAPHICAL METHOD FOR UNDERSTANDING THE EXPERIENCES AND \\ THE EXPRESSIONS RELATED BY PREGNANT WOMEN PATIENTS OF A HEALTH CARE SERVICE
}

\author{
EL MÉTODO BIOGRÁFICO INTERPRETATIVO EN LA COMPRENSIÓN DE EXPERIENCIAS Y \\ EXPRESIONES DE MUJERES EMBARAZADAS DE UN SERVICIO DE SALUD
}

Marta Maria Melleiro', Dulce Maria Rosa Gualda²

\begin{abstract}
RESUMO
Este trabalho fotoetnográfico teve por objetivo

compreender a experiência da mulher no seu contato com o sistema de saúde, por ocasião do parto. Os dados foram apresentados na forma de narrativa e a sua análise se deu através do Método Biográfico Interpretativo. Das narrativas foram extraidas oito categorias, das quais emergiram três temas culturais: "Classificando as experiências vividas,"

"Vislumbrando o processo de nascimento" e "Fotografando os eventos significativos." Os achados deste estudo permitiram ter uma visão compreensiva do conhecimento cultural das colaboradoras com relação à sua interação com o sistema de saúde, bem como de suas expectativas no ciclo gravídico-puerperal.
\end{abstract}

\section{PALAVRAS-CHAVE}

Sistema de saúde.

Parto.

Saúde da mulher.

\author{
ABSTRACT \\ This objective of this study \\ based on pictorial \\ ethnography is to understand \\ the experience of women in \\ their contact with the health \\ system during pregnancy. The \\ data were presented by \\ narrative and their analysis \\ was done based on the \\ Interpretative and \\ Biographical Method. From \\ the interviews eight cultural \\ categories were taken, from \\ which emerged three cultural \\ themes: "Classification of life \\ experiences," "Advancement \\ of the birth process" and \\ "Taking pictures of significant \\ events. "The findings allowed \\ for a comprehensive vision of \\ the particpants' cultural \\ knowledge related to their \\ interaction with the health \\ system, as well as their \\ expectations of the puerperal \\ gravid cycle.
}

\section{KEYWORDS \\ Health system. \\ Parturition. \\ Women's health.}

\author{
RESUMEN \\ Este trabajo fotoetnográfico \\ tuvo por objetivo comprender \\ la experiencia de la mujer \\ en su contacto con el sistema \\ de salud, con motivo del \\ parto. Los datos fueron \\ presentados en forma de \\ narrativa y su análisis por \\ medio del Método Biográfico \\ Interpretativo. Fueron \\ extraidas ocho categorías \\ de las que emergieron tres \\ temas culturales: \\ "Clasificando las experiencias \\ vividas," "Anticipando el \\ proceso del nacimiento” $y$ \\ "Fotografiando los eventos \\ significativos." Los hallazgos \\ de este estudio permitieron \\ una visión comprensiva del \\ conocimiento cultural de las \\ colaboradoras en relación a \\ su interacción con el sistema \\ de salud, asi como de sus \\ expectativas en el ciclo \\ gravídico-puerperal.
}

\author{
PALABRAS CLAVE \\ Sistema de salud. \\ Parto. \\ Salud de las mujeres.
}

\author{
* Extraído da Tese de \\ Doutorado \\ "Experiências e \\ Expressões de \\ Gestantes na Interação \\ com o Sistema de \\ Saúde: um enfoque \\ fotoetnográfico", Escola \\ de Enfermagem da \\ USP (EEUSP), 2003. \\ 1 Professor Doutor do \\ Departamento de \\ Orientação Profissional \\ da EEUSP. \\ melleiro@usp.br \\ 2 Professor Associado do \\ Departamento de \\ Enfermagem Materno \\ Infantil e Psiquiátrica da \\ EEUSP. \\ drgualda@usp.br
}




\section{INTRODUÇÃO}

No âmbito do Sistema Único de Saúde (SUS), o Programa de Assistência Integral à Saúde da Mulher (PAISM), elaborado em 1983, define uma política especial de atenção a ser oferecida à população feminina, propondo que os serviços de saúde prestem assistência às mulheres em todas as fases de suas vidas, de acordo com a especificidade de cada fase.

A concretização desse programa de assistência global à saúde da mulher passa pelo conceito de integralidade, um dos princípios do SUS, que prevê a integração interinstitucional e pela efetiva participação dos usuários no sistema de saúde.

No ciclo gravídico-puerperal, apesar da proposta de descentralização e das medidas preconizadas pelo PAISM, observa-se que as mulheres continuam enfrentando sérias dificuldades na busca de assistência qualificada própria para esse período.

Atuando na Divisão de Enfermagem Materno-Infantil do Departamento de Enfermagem do Hospital Universitário da Universidade de São Paulo (HU-USP), por quase duas décadas, a princípio desenvolvendo atividades assistenciais com gestantes, puérperas e seus neonatos e, posteriormente, assumindo o gerenciamento dessa divisão, pudemos perceber o quanto a dificuldade de integração existente entre os diferentes níveis de complexidade dos serviços de saúde, tornava estanque o aproveitamento dos recursos disponíveis em cada serviço.

Especificamente no que se refere à assistência à mulher no ciclo gravídico-puerperal, essa falta de integração entre os serviços de saúde, além de levar à ruptura das ações iniciadas nas Unidades Básicas de Saúde (UBS), durante o pré-natal, tornava a procura pela instituição hospitalar, por ocasião do parto, fonte de ansiedade e risco, com repercussões negativas para o processo de nascimento.

Essa evidência levou-nos a refletir e a questionar sobre o real significado que essas usuárias atribuíam aos serviços de saúde. Quais são as percepções dessas gestantes acerca da assistência ao ciclo gravídicopuerperal? Como se inserem nesse contexto e como o vivenciam? Que avaliação fazem do acesso aos serviços de saúde?
Assim, cientes da relevância da integração dos diferentes níveis de complexidade dos serviços de saúde e da necessidade do conhecimento das inquietações e expectativas das usuárias desses serviços, é que nos dispusemos a analisar as narrativas de gestantes usuárias do HU-USP, com o objetivo de compreender a experiência da mulher, no seu contato com o sistema de saúde, por ocasião do parto.

\section{A CONSTRUÇÃO DAS NARRATIVAS: PERCURSO METODOLÓGICO}

A narrativa é utilizada para entender eventos concretos, para relatar o mundo interior e o mundo exterior de ações observáveis e acontecimentos; o relato de experiências de pessoas, na forma de narrativa, é considerado valioso na clarificação e na interpretação do fenômeno estudado. Quando os indivíduos falam de suas experiências, eles utilizam a memória autobiográfica, que pode ser compreendida não como reprodução de eventos passados, mas como reconstruções congruentes à compreensão atual; o presente é explicado, tendo como referência o passado reconstruído e ambos são utilizados para gerar expectativas sobre o futuro ${ }^{(1)}$.

O processo de reconstrução que a narrativa desencadeia coloca os colaboradores do estudo na posição de autores e intérpretes de sua história, de suas emoções e de suas decisões ${ }^{(2)}$.

As narrativas, portanto, não são limitadas para a reconstrução do passado, mas são usadas para expressar a compreensão de um momento atual da vida de alguém e possivelmente para antecipar o futuro. Fornece, ainda, um forte meio para comunicar e dar significado à experiência.

As etnografias tradicionais que incorporam relatos na primeira pessoa são entendidas como descrições realísticas, diferindo somente no formato das outras descrições científicas. Embora a retórica da maneira de que como se escreve possa variar, a história escrita é o evento, e não a história que os informantes criam sobre ele ${ }^{(3)}$.

A partir de histórias gravadas, um pesquisador recorta das falas aquilo que se encaixa no conteúdo de um texto. Há decisões sobre a forma, ordem e estilo de apresenta- 
ção e de como os fragmentos da vida têm que ser obtidos das entrevistas que serão descritas. A resposta antecipada ao trabalho, inevitavelmente, molda o que é incluído ou excluído. No final, o pesquisador elabora uma pós-história, apontando o significado das narrativas, editando e reconstruindo o que foi dito ${ }^{(4)}$.

Neste estudo, após a aprovação da pesquisa e anuência para a coleta de dados pelo Comitê de Ética do HU-USP, as narrativas foram construídas a partir de entrevistas realizadas em duas etapas, com seis gestantes usuárias do referido hospital, no período de julho a setembro de 2002. Essas entrevistas se deram durante o pré-natal e no pós-parto, sendo que durante o pré-natal as gestantes tiveram a oportunidade de fotografar o citado hospital, durante uma visita a todos os setores que teriam contato por ocasião da internação para o parto.

As fotografias realizadas pelas gestantes subsidiaram as entrevistas e representaram uma transcrição livre e fragmentária de uma realidade a partir de uma deliberação extremamente pessoal, algo singelo ou corriqueiro que, resgatado de sua banalidade, adquiriu uma nova significação e pode, eventualmente, tornar-se uma síntese indicativa de uma realidade infinita mais complexa. Assim, o olhar fotográfico foi utilizado como um hábito visual seletivo, animado por uma percepção sensibilizada por motivações de diversas origens - filosóficas, ideológicas, culturais e afetivas ${ }^{(5)}$.

Nesse contexto, a produção fotográfica das gestantes deste estudo, cujos nomes fictícios adotados foram Ametista, Pérola, Cristal, Safira, Coral e Jade, permitiu aliar o ato de fazer fotografias com o que emergiu de suas emoções e de seus interesses. Assim, esse material fotográfico foi constituído por imagens da área física, de equipamentos, de usuários e de profissionais do HU-USP.

A partir dessas entrevistas foram construídas as narrativas, das quais foram extraídas oito categorias culturais, a saber:

a)O começo da vida: uma trajetória de eventos significativos;

b) O pré-parto: esperando o momento do nascimento;

c) Os sentimentos gerados pela sala de parto; d) O berçário: uma extensão do hábitat intrauterino;

e) $\mathrm{O}$ alojamento conjunto e a sensação de estar livre de riscos;

f) A repercussão da visita ao HU-USP;

g) Resgatando o valor da visita e da assistência recebida e

h) a Fotografia como instrumento de coleta e de análise dos dados.

Dessas oito categorias emergiram três temas culturais

a)Classificando as experiências vividas;

b) Vislumbrando o processo de nascimento e

c) Fotografando os eventos significativos,

referentes às experiências pessoais e às expectativas que as usuárias tinham, em relação à sua interação com o sistema de saúde. Para a análise desses temas culturais adotouse o Método Biográfico Interpretativo, que tem Norman Denzin como um de seus maiores expoentes.

\section{O MÉTODO BIOGRÁFICO INTERPRETATIVO: DESCRIÇÃOE ANÁLISE}

O Método Biográfico Interpretativo envolve o uso e a coleta de documentos da história de vida e de narrativas. $\mathrm{O}$ foco desse método reside nas experiências de vida, que alteram ou formam o significado de si mesmos e que tem como pressuposto básico a importância da interpretação e da compreensão como a chave que forma a vida social.

A adoção desse método ocorreu, também, após se constatar que as colaboradoras deste estudo recorriam à sua memória autobiográfica para elaborar a experiência presente, ou seja, os fatos vivenciados no passado eram trazidos e explicitados com base na sua compreensão atual. Nessa perspectiva é que nos dispusemos a compreender a experiência das colaboradoras na sua interação com o sistema de saúde.

A palavra método deve ser entendida como um caminho de conhecimento do mundo, podendo resultar dos embasamentos subjetivos, objetivos e intersubjetivos ${ }^{(6)}$.

O conhecimento subjetivo envolve a descrição da experiência pessoal ou da experiência
O método biográfico

interpretativo na

compreensão de

experiências e

expressões de

gestantes usuárias

de um serviço

de saúde 
Marta Maria Melleiro Dulce Maria Rosa Gualda de outras pessoas na compreensão de um fenômeno particular; o conhecimento objetivo assume que alguém que esteja fora da experiência, possa entendê-la independente de ter experenciado o fenômeno e o conhecimento intersubjetivo baseia-se na troca de experiências ou na aquisição de conhecimento por meio da participação em uma experiência comum.

O Método Biográfico Interpretativo se apóia nos conhecimentos subjetivos e intersubjetivos adquiridos e no entendimento da experiência de vida dos indivíduos. Sob essa ótica, as colaboradoras deste estudo estariam descrevendo não só a sua experiência pessoal, como, também, possibilitando o mapeamento e a interpretação dos aspectos comuns da mesma, refletindo a experiência do grupo cultural do qual fazem parte.

As autobiografias e biografias são expressões narrativas da experiência de vida. Essas convenções servem para definir a experiência de vida das pessoas e, embora sejam universais, podem ser diferenciadas ou ter a sua forma modificada dependendo de quem a escreve, do local em que é escrita e do momento histórico ${ }^{(6) .}$

As expressões narrativas da experiência de vida envolvem os seguintes pressupostos:

1) A existência do outro: a visão do outro interfere na visão do autor. Os textos são escritos sob duas perspectivas a do autor e a do outro. $\mathrm{O}$ olhar do outro direciona o olhar do autor;

2) Gênero e classe: as produções refletem valores e preconceitos e são, normalmente, representadas e defendidas pela perspectiva do autor;

3) Antecedentes familiares: as autobiografias e as biografias são baseadas na história da família. É como se todo autor de uma biografia ou autobiografia precisasse encontrar a origem [o marco zero] da vida que está sendo descrita;

4) Momentos marcantes textuais: por ser uma autobiografia ou um texto biográfico supõese que essa vida tenha um ponto de partida. Os estilos de autobiografia e biografia estão estruturados na crença de que a vida tem início na história da família;

5) Cumplicidade do autor: os textos supõem a presença de um autor ou de um observador externo, que pode registrar e dar sentido à biografia. Se o texto é autobiográfico entende-se que o próprio autor conhece o teor de sua vida e, portanto, está na melhor posição para escrever sobre ela. Os textos biográficos têm o mesmo pressuposto, onde o autor descreve sobre a vida de alguém, desde que conheça profundamente a vida desse alguém; 6) Marcas objetivas: refletem os pontos chaves e críticos da vida das pessoas;

7) A pessoa real: quando o biógrafo sugere detalhes objetivos da vida real de um indivíduo, ele está na verdade somente "criando" aquele sujeito no texto que está sendo escrito. Os métodos autobiográfico e biográfico baseiam-se na existência de um indivíduo e que se pode escrever sobre ele;

8) Experiências marcantes: certos momentos deixam marcas permanentes. A vida estará dividida em duas partes heterogêneas: antes e após o acontecimento. O conceito de que a vida gira ao redor de eventos significativos é chamado de epifania. Dessa forma, os textos autobiográficos e biográficos são estruturados pelos momentos significantes e pelas experiências marcantes da vida desse indivíduo;

9) Verdade: a vida tem objetivos e características documentárias.

Esses pressupostos estão implícitos nas narrativas das gestantes, uma vez que refletem as crenças, os valores e as idéias preconcebidas dessas mulheres com relação ao ciclo gravídico-puerperal. Traduzem, ainda, momentos marcantes de suas vidas, dividindo-as em duas partes: antes e após a interpretação que fazem do processo de nascimento.

Pérola descreve em sua narrativa uma situação vivenciada por ela, que reflete essa condição.

O meu primeiro parto foi há cinco anos e
tudo correu bem durante o pré-natal, mas
passou da hora da nenê nascer e então ela
teve insuficiência respiratória... E ela ficou
internada por mais de uma semana no hos-
pital, por um problema que poderia ter sido
evitado... Então sempre que entro em um
hospital isso me vem à cabeça... (Pérola)

Interpretar é o ato de dar sentido a algo, de criar condições para compreender, de ser capaz de entender os significados e de entender uma experiência interpretada por um outro indivíduo. Sendo assim, os estudos biográficos supõem que a vida pode ser estudada, construída, reconstruída e escrita. Nesse contexto, a vida engloba dois fenômenos: a pessoa e a experiência de $\operatorname{vida}^{(6)}$. 
A consciência do indivíduo é simultaneamente direcionada para o mundo interior de pensamentos e experiências e para o mundo exterior de eventos e experiências. A vida é vivida em dois níveis - o superficial e o profundo. No nível superficial, a pessoa é o seu cotidiano, suas rotinas; no nível profundo, a pessoa é o sentimento, a moral, as crenças, o eu interior. Neste nível, o eu interior não é freqüentemente mostrado aos outros e é por isso que os estudiosos de autobiografias e biografias podem capturar esse aspecto nos documentos autobiográficos e biográficos.

$\mathrm{O}$ depoimento a seguir mostra a importância da conjunção desses dois mundos no processo de experenciar.

Na minha primeira gravidez eu não tive conhecimento de nada, então quando as dores do parto começaram, fui para o hospital, tive o nenê e me deram alta, não explicaram nada para mim(...) Mas desta vez está sendo diferente, sinto que estou participando de tudo(...) Acho que estou sendo mais mãe e isso está sendo muito importante para mim. (Coral)

A vida é um projeto interminado ou um conjunto de projetos. Uma pessoa tem a tendência de organizar esses projetos ao redor de sua identidade ou de sua biografia pessoal. Dessa forma, a vida é propriedade biográfica, não pertencendo somente à pessoa, mas também à coletividade, à sociedade e ao mundo.

Toda vida é uma produção moral, política, técnica e econômica. Quando a vida é escrita, a história que é contada pode registrar as experiências de vida das pessoas, parcial ou totalmente; pode, ainda, ser editada focalizando somente um conjunto particular de experiências significativas, tais como as observadas nas narrativas a seguir.

Outra coisa que me chamou a atenção no berçário foram as mães amamentando. Veja as fotos que tirei dos quadros de mães amamentando. Porque existem pessoas que acham que a amamentação não é importante, que a mamadeira substitui o leite materno, na verdade não é nada disso. Sabe, hoje eu tenho uma experiência maior e sei o quanto é importante amamentar a criança, além disso eu acho tão bonito... Veja essa foto, para mim ela mostra a beleza que é a mulher amamentando...(Pérola)
Você não imagina o que é ter alta e deixar seu filho internado no berçário(...) Ele precisou ficar internado para ganhar peso, porque nasceu prematuro, pesando 1550 gramas, foram vinte e três dias(...) mas ele saiu bem. (Jade)

A vida possui três dimensões ${ }^{(7)}$ : como é vivida, como é experenciada e como é contada. Uma vida vivida é o que na verdade acontece; a vida experenciada consiste nas imagens, sentimentos, sensações, desejos, pensamentos e significados do conhecimento que a pessoa tem da vida e a vida contada - a história de vida - é uma narrativa influenciada pelas convenções culturais de quem está contando, de quem a ouve e do contexto social na qual está inserida.

Ametista relatou o medo que sentia em relação ao parto, derivado do seu contexto sócio-cultural:

\begin{abstract}
E ainda ouvimos tantas notícias ruins na televisão e nos jornais. Nessa semana mesmo ouvi que em uma maternidade do interior morreram cinco nenês por infecção hospitalar... Quando ouço essas coisas me sinto completamente vulnerável. (Ametista)
\end{abstract}

No entanto, não se deve adotar uma perfeita correspondência entre essas três formas e versões sobre a vida ${ }^{(6)}$. Certamente é possível imaginar uma vida como é vivida, experenciada e contada, se se acreditar no perfeito relacionamento entre essas três formas, entre o ideal e o real.

Há inevitáveis lacunas entre a realidade, a experiência e a expressão. Nesse sentido, deve-se estar alerta para essas lacunas e para os caminhos nos quais as pessoas e suas ideologias se encaixam ${ }^{(7)}$.

A experiência e a expressão são os encontros individuais, os confrontos, as passagens, e o que dá sentido aos eventos que acontecem nas vidas das pessoas. Com base nesse raciocínio, as mulheres atribuem significado às suas experiências, derivadas do seu contexto de vida. O contexto de vida é a matriz da relação ser humano-ambiente que surge ao longo do cotidiano ${ }^{(8)}$.

Nos relatos de Cristal e Safira pode-se observar a influência do contexto no qual estão inseridas.
O método biográfico interpretativo na compreensão de experiências e expressões de gestantes usuárias de um serviço de saúde 
Marta Maria Melleiro Dulce Maria Rosa Gualda
Ouço falar tantas coisas de parto e eu não estou falando só do atendimento dos médicos e sim do imprevisto, que eu posso passar mal (...) que meu nenê pode ter algum problema (...) eu tenho medo disso (...) Tenho medo do parto fórcipe, porque ouvi dizer que machuca a cabeça do nenê... já imaginou o nenê tão pequenininho e com dor... com a cabecinha toda machucada. (Cristal)

Sabe tenho medo que aconteça tudo de novo, porque da outra vez estava tudo bem durante o pré-natal e quando internei tive todo aquele problema [referindo-se ao fato de ter tido eclâmpsia]. Agora a médica pediu para eu tirar o sal da comida, para eu fazer repouso e é o que eu estou fazendo e quando vier ganhar o nenê, vou trazer o resumo de alta com tudo o que aconteceu no outro hospital. (Safira)

A partir dessa perspectiva, a experiência do parto de uma mulher é distinta da de outra e pode ser conhecida pela descrição subjetiva individual desta. Assim, a experiência do parto é um evento pessoal único que é impregnado pelo contexto. $\mathrm{O}$ depoimento abaixo ratifica essa premissa:

\section{Eu já ouvi muita história de parto, a minha tia teve um parto fórcipe que machucou a cabecinha do nenê, uma amiga minha tam- bém, o médico puxou o nenê com fórcipe e quebrou o seu bracinho, quando o parto é cesárea essas coisas não acontecem, não é mesmo? (Ametista)}

As experiências podem ser problemáticas, rotineiras ou ritualizadas e são expressas de várias maneiras, incluindo rituais, filmes, artigos científicos, canções e vidas escritas por meio de autobiografias e biografias. Em contrapartida, as expressões de experiências são formuladas por convenções culturais, a convenção que a vida tem começo e fim. Expressões são atividades processuais, que iniciam uma performance e assumem um papel cultural e de texto social.

As narrativas das experiências pessoais não necessariamente posicionam o eu do contador no centro da história, o seu foco está na experiência compartilhada. As narrativas das experiências pessoais são embasadas nas experiências comuns, rotineiras, todavia podem envolver experiências críticas de vida ${ }^{(6)}$.

Dessa forma, evidencia-se a importância da interpretação e da compreensão das experiências pessoais, para o entendimento do comportamento dos indivíduos. Para tanto, torna-se imperativo o estudo dessas experiências e desses eventos marcantes, que são chamados de epifanias.

As epifanias são experiências problemáticas ou momentos de revelação na vida de uma pessoa. Na epifania, características individuais são reveladas como uma crise ou um evento significativo que é confrontado ou experenciado.

As epifanias são momentos interacionais e experiências que deixam marcas nas vidas das pessoas. São normalmente momentos de crise, que alteram estruturas significantes na vida das pessoas. Seu efeito pode ser positivo ou negativo ${ }^{(6)}$.

Safira relatou a experiência de ter tido eclâmpsia e de não ter saído de alta com o seu bebê. Essa experiência deixou marcas, que foram resgatadas no momento da pesquisa.

No meu outro parto eu fui desacordada para
a sala de parto... tive o que vocês chamam
de eclâmpsia, a pressão subiu demais, tive
convulsão e os médicos tiveram que fazer
uma cesárea, eles disseram para o meu
marido que a pressão alta poderia estar
"queimando" o nenê... Mas ele nasceu bem,
tanto que teve alta antes de mim... Minha
mãe e meu marido levaram ele para casa e
eu fiquei internada durante uma semana.
Quando voltei fiz questão de cuidar dele,
amamentar... mas amamentei por pouco tem-
po, porque logo tive que trabalhar.(Safira)

A epifania é a fase crítica da experiência. São atos existenciais, onde alguns são ritualizados, como nos rituais de passagens, outros são ainda rotineiros. Outros são totalmente emergentes e sem estrutura e a pessoa os confronta com poucos conhecimentos prévios do que está para acontecer. Os significados dessas experiências são sempre retrospectivos como se fossem revividos e reexperenciados nas histórias das pessoas sobre o que aconteceu ${ }^{(9)}$.

As epifanias são classificadas em ${ }^{(10)}$ :

1) Epifania maior: interfere em toda a estrutura de vida da pessoa, provocando rupturas.

2) Epifania cumulativa ou representativa: diz respeito às reações que as pessoas têm frente a uma série de eventos, que vêm acontecendo por um longo período de tempo.

3) Epifania menor ou iluminativa: simbolicamente marca tensões ou momentos problemáticos em um relacionamento ou em uma situação de vida. 
4) Epifania reexperenciada: os significados são dados no reviver de uma experiência ou de um evento marcante. Os efeitos são imediatos, mas as conseqüências só aparecerão mais tarde, no reviver do acontecimento.

Nesse sentido, epifanias podem ser caracterizadas como momentos significativos que deixam marcas na vida, que têm potencial para criar experiências e que transformam a vida das pessoas. Através do registro dessas experiências o pesquisador é capaz de revelar os momentos de crise que ocorreram na vida dessa pessoa. Eles são normalmente interpretados como experiências marcantes. Tendo passado por essa experiência a pessoa jamais será a mesma ${ }^{(10)}$.

As epifanias ocorrem dentro de grandes arenas históricas, institucionais e culturais, que cercam a vida das pessoas, sendo identificadas as quatro estruturas ou tipos de momentos problemáticos existenciais, citados anteriormente. Esses quatro tipos podem fundamentar-se neles próprios. Um determinado evento pode em fases diferentes, na vida ou nas relações das pessoas ser primeiramente maior e depois cumulativo ou mais tarde, ainda, ser reexperenciado ${ }^{(6)}$.

Sendo assim, a experiência de vida das colaboradoras deste estudo pode ser analisada nos diferentes âmbitos da epifania. O parto pode ser considerado uma epifania maior, enquanto que o processo, até que ele aconteça, o pré-natal e o período de internação, por exemplo, podem se encaixar nas epifanias cumulativas ou menores.

Nas narrativas estão, ainda, incorporadas as epifanias reexperenciadas, onde muitas relatam histórias de uma experiência, que aparece no reviver desse evento, conforme o depoimento de Jade:

\begin{abstract}
Além disso, na minha última gestação, eu tive pré-eclampsia, a minha pressão subiu muito e os médicos tiveram que fazer uma cesárea de urgência, porque o nenê já não estava mais mexendo (...) Me disseram que por pouco ele não morre. Pensei nisso tudo quando entrei na sala de parto (...) Será que tudo aquilo poderia se repetir? (Jade)
\end{abstract}

Para entender a vida, as epifanias e as experiências pessoais que representam e moldam uma vida é necessário penetrar e entender essas grandes estruturas. Elas fornecem a linguagem, as emoções, as ideologias, os verdadeiros conhecimentos e experiências compartilhadas de como as histórias ocorrem.
Uma história é sempre um relato interpretativo, mas certamente toda interpretação é tendenciosa. Entretanto, narradores podem neglicenciar fatores estruturais importantes, que podem estar infringindo a vida do informante. Muitas vezes, as gestantes entraram em conflito por considerarem-se responsáveis por um determinado evento de sua história de vida ou por se acharem forçadas a fazer a história que vivenciaram.

O relato de Pérola aponta um desses conflitos.

\begin{abstract}
$\mathrm{Na}$ verdade, eles estavam querendo "tapar o sol com a peneira," porque tinha erro e erro deles, porque eles me deixaram muito tempo com as dores do parto, acho que deveriam ter feito a cesárea antes, porque eu procurei o hospital (...), para que o bebê não tivesse tido esse problema. (Pérola)
\end{abstract}

As histórias sempre vêm em versões múltiplas e nunca têm começo e final claros; são baseadas na cultura de um grupo, onde critérios de veracidade são estabelecidos. As histórias contadas nunca são as mesmas histórias ouvidas, são moldadas por amplas forças ideológicas que pressionam as pessoas a estabelecer sua individualidade nas histórias que constroem ${ }^{(10)}$.

A vida e suas experiências são representadas em histórias; são como pinturas que foram cobertas e que quando essas pinturas são removidas algo novo se torna visível. O que é novo é o que estava previamente coberto. Uma vida e a sua história têm as qualidades do pentimento [mudança feita pelo pintor em seu quadro que se traduz em um retoque, em uma modificação ou em um refazimento. Vestígio de uma composição anterior ou de alterações em um quadro, tornadas visíveis em pinturas a óleo com a passagem do tempo]. Algo novo está sempre entrando em cena, deslocando o que estava previamente exposto. Não há exatidão na pintura da vida, somente imagens múltiplas e traços do que aconteceu, do que poderia ter acontecido e do que é agora. Essas histórias se movem para fora das próprias pessoas para os grupos que proporcionam significado e estrutura ${ }^{(10)}$.

Sob essa ótica, as pessoas são árbitros de sua própria presença no mundo e por isso devem ter a última palavra sobre ela. Os textos produzidos pelos pesquisadores devem sempre refletir os discursos das pessoas como se elas tentassem dar significado e forma para as suas histórias ${ }^{(10)}$. Essas histórias são aprendidas e contadas nos grupos culturais. As histórias que os membros dos grupos passam de um para outro são reflexões do conhecimento e da prática que são trabalhadas em um amplo
O método biográfico interpretativo na compreensão de experiências e expressões de gestantes usuárias de um serviço de saúde 
Marta Maria Melleiro Dulce Maria Rosa Gualda sistema de entendimento cultural, que são influenciadas pelos membros dos grupos.

Esses conhecimentos contêm concepções da vida das pessoas e suas experiências devem ser representadas. As histórias são contadas e ouvidas e solucionam os dilemas sobre a metafísica da presença que persegue o indivíduo, como ele tenta dar significado para o que é chamado de vida e biografia.

Ametista, ao mesmo tempo em que discorre sobre as idiossincrasias do grupo cultural do qual faz parte, aponta para um evento comum a todas: a ansiedade em decifrar o que, naquele momento, lhe é obscuro.

Fomos as últimas a chegar (...) [referindose à visita ao HU-USP]. Cada uma de nós com uma história diferente, com seus medos, suas inseguranças (...) O quê iríamos encontrar nessa visita? Qual seria nossa reação frente a tudo que mostrassem para nós? Afinal era o local indicado para o nascimento de nossos filhos (...) e, isso deixava todas nós muito ansiosas...(Ametista)

Quando escrevemos sobre a vida das pessoas trazemos o mundo dessas pessoas para os nosso texto. Criam-se diferenças, oposições e presenças, que permitem manter a ilusão de se capturar as experiências reais das pessoas. Na verdade, criam-se pessoas, sobre as quais se escreve a respeito, assim como essas pessoas criam-se a si próprias quando se empenham na prática de contar histórias. ${ }^{(6)}$ Por conseguinte, torna-se imperativo aprender como conectar biografias e experiências vividas, as epifanias das vidas com os grupos e

\section{REFERÊNCIAS}

(1) Garro LC. Narrative representations of chronic illness experience: cultural models of illness, mind and body in stories concerning the temporomandibular joint. Soc Sci Med 1994; 38(6): 775-88.

(2) Blasco JS. Estudio de casos. In: Baztán AA. Etnografía: metodología cualitativa en la investigación sociocultural. Barcelona: Marcombo; 1995. p. 203-8.

ecebido: $17 / 06 / 2003$ Aprovado: 01/09/2003

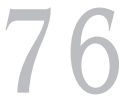

Rev Esc Enferm USP 2003; 37(4): 69-76

(3) Atkinson P. The ethnographic imagination: textual constructions of reality. New York: Routledge; 1990.

(4) Riessman CK. Narrative analysis: qualitative research methods. Newbury: Sage; 1993.

(5) Humberto L. Fotografia, a poética do banal. Brasília: Ed. Universidade de Brasília; 2000. relacionamentos sociais que fazem parte do contexto e que moldam as pessoas.

\section{CONSIDERAÇÕES FINAIS}

Face ao exposto, é na esfera do Método Biográfico Interpretativo que os temas culturais extraídos deste estudo encontraram sustentação, onde as colaboradoras, a princípio, resgataram e classificaram, por meio da sua memória autobiográfica, as suas experiências e as suas histórias de vida, na condição de manter os resultados dos eventos significativos considerados positivos ou de fazer uma releitura dos eventos tidos como negativos. A partir dessa concepção, as colaboradoras prosseguiram vislumbrando o processo de nascimento em todas as suas dimensões, utilizando, para o alcance dessa finalidade, o olhar fotográfico, que ora permitiu que fatos fossem registrados e absorvidos e ora evitou que suas lentes captassem aquilo que seria difícil elaborar naquele momento.

Levando-se em conta o que foi apresentado, durante esta investigação procuramos compreender e relatar as experiências, as expressões e as expectativas de gestantesusuárias do HU-USP, cientes de que as narrativas possuem dados a serem, ainda, processados, uma vez que assim como a vida, as narrativas são sempre infindáveis e sujeitas a múltiplas interpretações. Todavia, acreditamos ter escrito sobre documentos de vida, que carregam os sentimentos dessas mulheres.

(6) Denzin KN. Interpretive biography. London: Sage; 1989a.

(7) Bruner EM. Experience and its expressions. In: Denzin NK. Interpretive biography. London: Sage; 1984. p. 30-33.

(8) Marcus MT, Liehr PR. Abordagens de pesquisa qualitativa. In: LoBiondo-Wood G, Haber J. Pesquisa em enfermagem: métodos, avaliação crítica e utilização. Rio de Janeiro: Guanabara Koogan; 2001. p. 122-139.
(9) Turner V W, Bruner EM. The antropology of experience. Urbana: University of Illinois Press; 1986.

(10) Denzin NK. Interpretive interactionism. London: Sage; 1989 b. 